\title{
Development of Listening and Linguistic Skills through the Use of a Mobile Application
}

\author{
Lizeth Ramos $^{1} \&$ Arturo Valderruten ${ }^{1}$ \\ ${ }^{1}$ Faculty of Education, Santiago de Cali University, Cali, Colombia \\ Correspondence: Lizeth Ramos, Faculty of Education, Santiago de Cali University, Cali, Colombia. E-mail: \\ 1ramos@usc.edu.co
}

Received: June 1, 2017 Accepted: August 3, 2017 Online Published: August 8, 2017

doi: 10.5539/elt.v10n9p95 URL: http://doi.org/10.5539/elt.v10n9p95

\begin{abstract}
The purpose of this article is to present the results of a research that was developed with eight groups of students of undergraduate programs of the Language Institute at Santiago de Cali University. The research was developed with four groups of students who used a mobile application developed jointly by foreign language professors, a software development professor and systems engineering students, as a support tool for individual practice of English level 1 (Test groups) and an equal number of groups of students who did not use the application (Control groups). No mobile applications already available in the market were used because none of them fit the sequence of topics that the course develops along the semester, thus, it was necessary to design an application tailored to the different themes, grammar and vocabulary requirements that were developed by the students. In both cases, a written test was performed at the beginning and end of the course in order to establish the benefit that the application could offer to the students in the test groups. The results indicate that the frequent use of the mobile application might have a positive impact on the development of both listening and linguistic competencies of English.
\end{abstract}

Keywords: mobile learning, gamification, English, app

\section{Introduction}

The use of a foreign language is now the main requirement for professionals in Colombia, in order to respond to the needs that the globalized world poses and access better work positions, or be able to carry out academic and economic exchanges. To this end, the Ministry of National Education has developed the 2015-2025 National Program of English "Colombia Very Well", within the framework of the Law of Bilingualism (Law 1651 of 2013), which seeks to promote the learning of English to strengthen the communicative competence of citizens and take advantage of the opportunities offered by free trade agreements, competitiveness, mobility and the flexibility of the current labor market. The aim of this program is to increase from 6000 to 18000 the number of bilingual teachers with high-intermediate level (B2) of the Common European Framework of Reference for Languages (CEFRL), and to increase from 9000 to 186000 the number of intermediate-level B1, and from 55000 to 140000 the number of graduates of the universities with level B2. Similarly, the Ministry of Commerce, Industry, and Tourism has sought to create a national database through the "I speak" calls, to offer or link people with a high level of English to different companies.

According to data from the English Proficiency Index (EPI) for 2015, Colombia ranks $57^{\text {th }}$ out of 70 countries in the world according to the English level of those assessed. Colombia ranks $12^{\text {th }}$ among 14 countries with a very low level of performance compared to other Latin American countries. EPI is an EF data source (English First), an entity that measures the English proficiency index worldwide through a test that is applied each year to a statistically representative number of adults. By 2014, 910,000 people from Europe, Asia, Latin America, the Middle East and North Africa were evaluated through an online exam that measured language skills and reading comprehension in English. The free exam was taken by men and women under the age of 60. This shows that the level of English proficiency in the country continues to be very low.

In addition, according to data presented in a study on Bilingualism in Colombia that was carried out by the Bank of the Republic, $90 \%$ of high school graduates reached A1 level according to the CEFRL and only $2 \%$ of students finishing their education studies had a B1 average level of proficiency that was the current goal expected by the Ministry of National Education under the program "Colombia Bilingüe", predecessor of the 
current program, which has significantly raised these goals." In higher education only $6.5 \%$ reach the above-mentioned level.

According to this study, the "Colombia Bilingüe" project aimed, as well as the "Colombia Very Well" program, to promote the learning process of English. Within the goals set by this project, by 2019 it is expected that in the education sector, high school graduates will reach the B1 level and all graduates of the higher education level should reach B2. However, the same study reveals that Colombia is a low-level country of both students and teachers and there is little feasibility in meeting the goals set to the process of bilingualism that is expected to be achieved in the country.

In Valle del Cauca region, ordinance number 345 of the Departmental Assembly, structure, and concrete the public policy of bilingualism in the Valley and municipal agreement number 326 of 2012 dictate the guidelines for the institutionalization of the program: Training for a global citizen and Creates the "Cali Bilingüe" committee. The common denominator is that the national, regional and municipal governments give priority to the teaching and learning of a foreign language (English) by promoting different plans and projects to achieve the improvement of students' language sufficiency levels.

Due to the current needs and demands at the local, national and international level regarding fluency and correct use of at least one foreign language, Santiago de Cali University (USC) offers the foreign language courses to all the academic programs of the institution through the Institute of Languages as an indispensable requirement for the comprehensive training of undergraduate students, with a student population of approximately six thousand. Through resolution CA 009 of June 18, 2013, the USC established as a mandatory graduation requirement for all students of the institution's programs to hold level B1.

The Languages Institute offers a placement test to all students of the the first semester. The test determines the level of English with which the students enter and thus they are located in the corresponding course according to the program established by the University.

According to results of the English language test conducted by the Languages Institute, in semester $2013 \mathrm{~B}, 82 \%$ of university candidates to the first semester registered A1 and in semester 2014A, the percentage of students who entered the university in the first semester with level A1 was of $88,5 \%$.

The results of this English placement test show that students come to the university with a low level to continue the process of language learning, hence, the urgency of generating didactic strategies allowing a high percentage of students to level their knowledge of the English language.

The research project entitled "Development of listening and linguistic skills through the use of a mobile application", aimed at designing, developing and implementing a free mobile application for the practice and improvement of the listening and linguistic competencies of those students placed at level A1 at Santiago de Cali University.

The research project was developed to offer students entering their first academic semester a free mobile application that allows them to meet possible deficiencies in vocabulary, grammar and listening in the foreign language and thus improve their learning performance. The use of a mobile application for educational purposes, including and game elements (gamification) not only contributed to the improvement of the skills already mentioned but also had a positive impact on the motivation of students to learn English.

This article presents in its first part a brief conceptualization about m-learning (mobile learning) and gamification, its origin, the elements that compose it and how these elements are implemented in educational contexts. The second part describes the methodology that was used for the development of the research. The results of the research are shown - which are discussed in comparison with similar studies carried out in other countries - and finally, the conclusions are presented.

Before addressing the concept of gamification, it is necessary to refer to the use of technology in education, from a general scope, and in particular to the release of mobile applications in the last five years in educational contexts.

According to a UNESCO report entitled "The Future of Mobile Education" (2013) technology has changed our world in multiple and unimaginable ways. Mobile phone use permeates our daily lives. By the end of 2012, it was estimated that the number of mobile devices would have exceeded the world population. As the power, applicability and easy access to these equipment increases so does its potential as a support for learning in multiple areas.

The same paper argues that the design of effective mobile interventions for learning requires a holistic 
understanding of how technology is inserted in social, cultural and academic contexts. Recently, in the educational field, mobile devices have been banned in schools and other educational centers. During the last fifteen years, however, the implementation of educational projects using mobile devices has increased.

It has been demonstrated that the use of mobile devices has a high potential for transforming educational experiences and learning outcomes. In the same document mentioned above, mobile devices such as tablets and smartphones will be available to a greater number of people by 2030, and in the educational field, these devices will be directed to the learning process of all age groups.

Currently, both students and teachers use mobile technologies in different contexts for a wide variety of teaching and learning purposes. The use of devices and mobile technology for learning (m-learning) has been increasing in the last decade, especially in higher education institutions. Osman et al. (2010) define m-learning as any type of learning process that takes place in environments and learning spaces that take into account the use of mobile technology, student mobility, and learning mobility. According to the SCOPEO Monographic No.3 report entitled "m-learning in Spain, Portugal, and Latin America" (2011) this type of learning facilitates the creation of learning communities; Favors interaction and collaboration among participants; Allows learning focused on the student's environment and context; Allows direct publication of content, observations and reflections on students' performance; Improves confidence and self-esteem, and emphasizes self-directed and differentiated learning. The use of mobile technologies both inside and outside the classroom allows students to increase their motivation as these devices are considered everyday tools for so-called digital natives.

Patten, Sanchez and Tangney (2006) suggest that the literature on mobile learning technologies (mLearning technologies) have broad potential to facilitate learning in pedagogic environments considering that this type of learning can be accessed from anywhere and students can get involved quickly in an active type of learning that favors the development of critical thinking and problem solving.

Another benefit of mobile learning technologies according to Beishuizen (2008) is the possibility of increasing self-regulation of students defined as an individual trait of learners that allows them to recognize a need for learning, make decisions and maintain motivation towards learning. In addition, Muller, et al. (2012) explain that mobile technologies have the potential to facilitate outside learning activities with a high impact on motivation.

As for mobile applications, a study by the Entertainment Software Association, (2013) ESA, shows that 58\% of North Americans play video games spent an average of $\$ 20.77$ billion in 2012, which means that access to the internet and mobile phones have increased exponentially in recent years in developed countries. The scope of the games has been studied by Ma et al. (2011), finding that educational applications allow the deepening and efficient transmission of knowledge due to its low cost and the possibility of being used in conjunction with other learning methods.

One of the main reasons for mobile applications is the availability of users because there are no barriers or restrictions of time or space for access (during breaks, between daily activities, during the time of travel in public transport, Etc.) so it is more common today to see people making use of their connectivity. The main advantage of using applications is portability and connectivity because the student has unlimited access to interaction resources of any time and space.

In the field of educational technology, the most recent innovations in mobile technology have focused on creating digital content in the form of accessibility texts via online readers, the development of mobile applications (apps) and platforms for accessing resources Education through mobile devices. In this context, Garcia P. et al. (2013) emphasize the importance of pedagogical expertise in the design and creation of educational software, since in many cases, it is observed that the proposals lack an approach that allows users learn while they entertain. In the particular case of the present investigation, the application was developed thanks to the interdisciplinary work of two English-speaking teachers, an expert in software development and three students in the USC systems engineering program.

The concept of gamification - according to Deterding et al (2011) has its origins in the digital media industry. Its earliest documented uses date back to 2008 but its adoption in the field of technology had a boost in the second half of 2010 when several conferences and games industries popularized it.

The term gamification and its current uses seem to fluctuate between two perspectives: the first one is the social adoption and institutionalization of video game and the influence of games and game elements on the interactions of daily life

Zichermann and Cunningham (2011) define Gamification as the thought process of games and game mechanics to engage users and solve problems. There is now a growing interest in gamification and its applications. Its 
implications in the field of education, in particular, provide an alternative to motivate and engage students in their own learning process. In addition, Jordan (2012) argues that traditional education is evolving through a transition from a formal, institutionalized and static model to innovative, dynamic and social learning environments, in which the use of elements and game mechanics contribute to the performance of student's academic achievement and motivation towards learning. The implementation of the concept of gamification in education emerges as a new way to create meaningful experiences in formal and informal contexts of learning. Other authors such as Lee and Hammer (2011) define the gamification concept not only as the use of mechanisms, dynamics, and frameworks of games that promote desired behaviors in order to use the motivational power of games and incorporate them into situations and problems of the real world.

The use of gamification associated with interactive multimedia applications, and more recently on mobile devices has also great potential in language teaching. According to Jovanovic et al. (2011), the key is to construct an educational game based on a research specifically oriented to measure the learning regarding the motivation of the students. To this end, the educational games meta-model is proposed (EGM), which defines the basic concepts for the development of multiplatform educational games.

In addition, Glover (2013) argues that before implementing the concept of gamification in education it is necessary to consider whether student motivation is a problem, whether it is necessary to encourage some specific behaviors, whether it is possible to create a parallel evaluation route, what elements of gamification will favor more certain types of students, what kind of incentives will generate greater motivation in students and how easy to obtain are the rewards. The issues raised above provide greater clarity about the process of implementing gamification in education, taking into account that this is a process that allows the generation of participatory learning experiences, and constitutes a framework for the use of different types of resources to activate the learning process.

Consequently, it is possible to apply the concept of gamification in education, specifically in the process of learning a foreign language, in the development of the research project mentioned by the following phases proposed by Wendy Hsin-Yuan Huang and Dilip Soman (2013): To have a clear scope of the context: it is necessary to know in detail who the student is and what the context within which the educational program is developed is. This is a factor that determines the success or failure of the implementation of gamification elements. To define the learning objectives: it is indispensable to have clear goals that the student must achieve at the end of the program. To structure the experience: it is imperative to establish phases or stages in which students must achieve partial progress or learning achievements.

To identify the resources: it is fundamental to identify what mechanisms or elements of gamification, rules and/or feedback are going to be implemented. To apply gamification elements: it is possible to include reward icons for individual performance or competition features for group interaction. The former, recognize the student's progress through points, medals, trophies or other symbols. The latter places the student within a community whose progress is evidenced in public ranking scores.

An additional phase was included in the research project which consisted of evaluating the experience. The students who used the application answered a survey in order to know their opinions about the operation, benefit, and content of the application. This information is shown in the results.

In general terms, Aguilera, Fúquene and Ríos (2014) explain that the goal of gamification is not simply to use the intrinsic instinct of the human being for the taste of the game to motivate him to play, through the use of elements of gamification, the subject engages in a ludic activity to improve their abilities, skills or knowledge as well as motivation towards learning, in this case, English. Although there are many English learning applications available in the market, the purpose of this research was to create one that followed the sequence of topics that the English program at the Santiago de Cali University's Languages Institute follows, including local examples and cultural references that would be familiar to students.

\section{Method}

The main objective of the project was to measure the impact of the use of the mobile application among the students and to further explain this impact in the improvement of their linguistic and listening competencies. To achieve this purpose, the researchers implemented a placement test to know the level of students in terms of vocabulary, grammar, and listening skills. This assessment was applied to all groups selected as a sample. The research was framed in the type of explanatory research since it was intended to establish the impact of the use of the contextualized mobile application in the process of learning the foreign language of students of level A1. The research method chosen was a scientific and mixed approach (quantitative and qualitative). The groups of students who participated in this research were previously informed about the objectives of the same and were 
asked to participate in it without having this participation result in a numerical value in their final grade because it is a study in development. To prevent students from the test group from sharing the application with those in the control group, or with others, a confidentiality agreement was signed with each one, which was effective during the development of the research project. Likewise, the identity of the students involved in this research was protected at all stages of the research (surveys, use of the application, etc.).

\subsection{Participant (Subject) Characteristics}

For the development of this project, a sample of approximately 113 students of English A1 courses of the Language Institute of at Santiago de Cali University was chosen. The groups of students who used the application were the test group and the control group corresponded to those who did not use the application. The test was performed for all students at two stages of the project: before the students of the control groups had access to the mobile application and to the end of the course, after its use. The test took into account the component of listening skills, grammar, and vocabulary and was designed with a total of 28 questions. A former placement test was regularly applied at the beginning and end of the semester (Cambridge University Press test) was adapted by the researchers.

\subsection{Sampling Procedures}

In order to achieve a correct measurement of the improvement of the listening and linguistic competencies of students, the research presented here was framed in eight groups of students of English level A1. The assessed population of 113 students was divided into four control groups, consisting of a total of 60 students and four experimental, or test groups, with a total of 53 students. The results of the tests were verified through Analysis of Variance (ANOVA). This analysis is used to test the hypothesis that: "Sample arithmetic means of two or more populations that are the same or different".

That is to say:
Нo: $\overline{x_{1}}=\overline{x_{2}}=\overline{x_{3}}=\ldots \ldots=\overline{x_{n}}$
Ha: $\overline{x_{1}} \neq \overline{x_{2}} \neq \overline{x_{3}} \neq \ldots \ldots \neq . \neq \overline{x_{n}}$

To verify the hypotheses Null and Alternate Hypothesis (Ho and $\mathrm{Ha}$ ), in the analysis of variance it is necessary to perform the following procedures:

To test the hypothesis that: "The average assessments in both groups are not equal, therefore," The students of the A1 level at Santiago de Cali University, when using the application, students obtain better academic results than those using the traditional methodology " This analysis has a confidence level of $95 \%$.

Information processing:

Being: X1: Control Groups

$\mathrm{X} 2$ : Experimental Groups 


\begin{tabular}{|c|c|c|c|c|c|c|}
\hline & $x_{1}$ & $x_{2}$ & $x_{1}-x_{1}$ & $\left(x_{1}-\overline{x_{1}}\right)^{2}$ & $x_{2}-x_{2}$ & $\left(x_{2}-\overline{x_{2}}\right)^{2}$ \\
\hline & 42 & 39 & 15.75 & 248.0625 & 6.6792 & 44.6123176 \\
\hline & 26 & 23 & -0.25 & 0.0625 & -9.3208 & 86.8764685 \\
\hline & 35 & 29 & 8.75 & 76.5625 & -3.3208 & 11.0274119 \\
\hline & 19 & 30 & -7.25 & 52.5625 & -2.3208 & 5.38590246 \\
\hline & 25 & 42 & -1.25 & 1.5625 & 9.6792 & 93.6877892 \\
\hline & 19 & 46 & -7.25 & 52.5625 & 13.6792 & 187.121752 \\
\hline & 19 & 40 & -7.25 & 52.5625 & 7.6792 & 58.9708081 \\
\hline & 26 & 39 & -0.25 & 0.0625 & 6.6792 & 44.6123176 \\
\hline & 20 & 32 & -6.25 & 39.0625 & -0.3208 & o.10288359 \\
\hline & 16 & 21 & -10.25 & 105.0625 & -11.3208 & 128.159487 \\
\hline & 23 & 33 & -3.25 & 10.5625 & 0.6792 & 0.46137415 \\
\hline & 21 & 39 & -5.25 & 27.5625 & 6.6792 & 44.6123176 \\
\hline & 14 & 46 & -12.25 & 150.0625 & 13.6792 & 187.121752 \\
\hline & 23 & 19 & -3.25 & 10.5625 & -13.3208 & 177.442506 \\
\hline & 20 & 37 & -6.25 & 39.0625 & 4.6792 & 21.8953364 \\
\hline & 21 & 42 & -5.25 & 27.5625 & 9.6792 & 93.6877892 \\
\hline & 23 & 31 & -3.25 & 10.5625 & -1.3208 & 1.74439302 \\
\hline & 20 & 38 & -6.25 & 39.0625 & 5.6792 & 32.253827 \\
\hline & 24 & 28 & -2.25 & 5.0625 & -4.3208 & 18.6689213 \\
\hline & 39 & 31 & 12.75 & 162.5625 & -1.3208 & 1.74439302 \\
\hline & 28 & 35 & 1.75 & 3.0625 & 2.6792 & 7.17835529 \\
\hline & 32 & 32 & 5.75 & 33.0625 & -0.3208 & 0.10288359 \\
\hline & 36 & 38 & 9.75 & 95.0625 & 5.6792 & 32.253827 \\
\hline & 24 & 32 & -2.25 & 5.0625 & -0.3208 & o.10288359 \\
\hline & 26 & 50 & -0.25 & 0.0625 & 17.6792 & 312.555714 \\
\hline & 30 & 22 & 3.75 & 14.0625 & -10.3208 & 106.517978 \\
\hline & 35 & 19 & 8.75 & 76.5625 & -13.3208 & 177.442506 \\
\hline & 40 & 41 & 13.75 & 189.0625 & 8.6792 & 75.3292987 \\
\hline & 26 & 16 & -0.25 & 0.0625 & -16.3208 & 266.367035 \\
\hline & 42 & 27 & 15.75 & 248.0625 & -5.3208 & 28.3104308 \\
\hline & 15 & 24 & -11.25 & 126.5625 & -8.3208 & 69.2349591 \\
\hline & 26 & 28 & -0.25 & 0.0625 & -4.3208 & 18.6689213 \\
\hline & 21 & 39 & -5.25 & 27.5625 & 6.6792 & 44.6123176 \\
\hline & 30 & 18 & 3.75 & 14.0625 & -14.3208 & 205.084016 \\
\hline & 39 & 31 & 12.75 & 162.5625 & -1.3208 & 1.74439302 \\
\hline & 18 & 30 & -8.25 & 68.0625 & -2.3208 & 5.38590246 \\
\hline & 22 & 24 & -4.25 & 18.0625 & -8.3208 & 69.2349591 \\
\hline & 22 & 34 & -4.25 & 18.0625 & 1.6792 & 2.81986472 \\
\hline & 30 & 36 & 3.75 & 14.0625 & 3.6792 & 13.5368459 \\
\hline & 25 & 26 & -1.25 & 1.5625 & -6.3208 & 39.9519402 \\
\hline & 32 & 25 & 5.75 & 33.0625 & -7.3208 & 53.5934496 \\
\hline & 32 & 43 & 5.75 & 33.0625 & 10.6792 & 114.04628 \\
\hline & 20 & 32 & -6.25 & 39.0625 & -0.3208 & 0.10288359 \\
\hline & 19 & 36 & -7.25 & 52.5625 & 3.6792 & 13.5368459 \\
\hline & 17 & 26 & -9.25 & 85.5625 & -6.3208 & 39.9519402 \\
\hline & 12 & 25 & -14.25 & 203.0625 & -7.3208 & 53.5934496 \\
\hline & 5 & 27 & -21.25 & 451.5625 & -5.3208 & 28.3104308 \\
\hline & 50 & 42 & 23.75 & 564.0625 & 9.6792 & 93.6877892 \\
\hline & 25 & 33 & -1.25 & 1.5625 & 0.6792 & 0.46137415 \\
\hline & 18 & 40 & -8.25 & 68.0625 & 7.6792 & 58.9708081 \\
\hline & 36 & 34 & 9.75 & 95.0625 & 1.6792 & 2.81986472 \\
\hline & 33 & 38 & 6.75 & 45.5625 & 5.6792 & 32.253827 \\
\hline & 34 & 25 & 7.75 & 60.0625 & -7.3208 & 53.5934496 \\
\hline & 38 & 1713.00 & 11.75 & 138.0625 & & \\
\hline & 32 & & 5.75 & 33.0625 & & \\
\hline & 34 & & 7.75 & 60.0625 & & \\
\hline & 39 & & 12.75 & 162.5625 & & \\
\hline & 25 & & -1.25 & 1.5625 & & \\
\hline & 17 & & -9.25 & 85.5625 & & \\
\hline & 15 & & -11.25 & 126.5625 & & \\
\hline$x_{1}$ & $\begin{array}{c}26.25 \overline{x_{2}} \\
1575\end{array}$ & $=32.32$ & o & $\begin{array}{c}4565.25 \\
\Sigma\left(x_{1}-x_{1}\right)^{2}\end{array}$ & o & $\begin{array}{l}3261.54717 \\
\sum\left(x_{2}-x_{2}\right)^{2}\end{array}$ \\
\hline
\end{tabular}

$\mathrm{m}=\mathbf{2}$ (The control and test groups are grouped to facilitate the data analysis)

$\mathrm{n}_{1}=\mathbf{6 0}$ y $\mathrm{n}_{2}=\mathbf{5 3}$

It raises the null hypothesis Ho, and research or alternatively hypothesis Ha, thus: 
a. Ho: $\overline{x_{1}}=\bar{x}_{2}$ The average scores of both groups are the same, which means that: "English Level A1 students at Santiago de Cali University DO NOT OBTAIN better academic results when using the application"

b. Ha: $\overline{x_{1}} \neq \bar{x}_{2}$ " The students of level A1 at Santiago de Cali University GET better academic results when using the application than those using the traditional methodology"

Once the hypotheses are presented, the global mean is obtained by the following procedure:

$$
\bar{x}=\frac{\sum_{i=1}^{2}\left(\sum x_{i}\right)}{\sum_{i=1}^{2} n_{i}}=\frac{\sum x_{1}+\sum x_{2}}{n_{1}+n_{2}}=\frac{1575+1713}{60+53}=\frac{3288}{113}=29,097
$$

Subsequently, the variance among the columns (VAC) is established, as follows:

$$
\begin{aligned}
V A C=\frac{\sum_{i=1}^{2} n_{i}\left(\overline{x_{i}}-\bar{x}\right)^{2}}{m-1} & =\frac{n_{1}\left(\overline{x_{1}}-\bar{x}\right)^{2}+n_{2}\left(\overline{x_{2}}-\bar{x}\right)^{2}}{m-1}=\frac{60(26,3-29,1)^{2}+53(32,3-29,1)^{2}}{2-1} \\
& =\frac{486,4+550,6}{1}=1036,99
\end{aligned}
$$

And the value of the variance within the columns (VWC) is found as follows:

$$
V W C=\frac{\sum_{i=1}^{2}\left[\sum\left(x_{i}-\overline{x_{i}}\right)^{2}\right]}{\sum_{i=1}^{2}\left(n_{i}-1\right)}=\frac{\sum\left(x_{1}-\overline{x_{1}}\right)^{2}+\sum\left(x_{2}-\overline{x_{2}}\right)^{2}}{\left(n_{1}-1\right)+\left(n_{2}-1\right)}=\frac{456,3+326,6}{(60-1)+(53-1)}=\frac{782,8}{111}=70,5
$$

The calculated $\mathrm{F}$ value is set $(\mathrm{Fc})$, defined by:

$$
F_{c}=\frac{V A C}{V W C}=\frac{1036,99}{70,51}=14,71
$$

The value of $\mathrm{F}$ is tabulated $(\mathrm{Ft})$ which is defined by:

$\mathrm{Ft}=\mathrm{F} \alpha$, Vnumerator, Vdenominator

Where: $\alpha=5 \%=0.05$

Vnumerator $=\mathrm{m}-1=2-1=1$

Vdenominator $=\sum_{i=1}^{2}\left(n_{i}-1\right)=(\mathrm{n} 1-1)+(\mathrm{n} 2-1)=(60-1)+(53-1)=111$

Thus: $\mathrm{Ft}=\mathrm{F} 0.05 ; 1 ; 111=3,92$

The Hypothesis test or statistical decision is plotted: 


$$
\begin{gathered}
\boldsymbol{\beta}=\mathbf{9 5 \%} \\
\alpha=\mathbf{5 \%} \\
F_{c o}=14,71 \quad F_{T}=3,92
\end{gathered}
$$

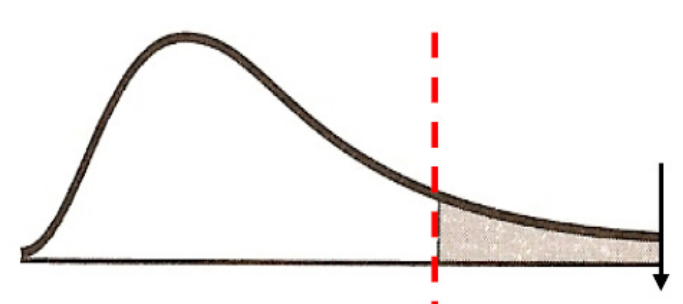

I

Since $F_{c}=14,71$ is found in the critical area (CA), then the alternative Hypothesis Ha, which reads: "The average values obtained by the experimental groups (those who used the application) are different from those obtained in the control groups (traditional methodology), which means that it has been demonstrated that students belonging to the test groups achieved a better performance of the competencies mentioned above. These results can be attributed to the continuous use of the mobile application, with a confidence level of $95 \%$, with one degree of freedom in the numerator, and 111 degrees of freedom in the denominator.

\subsection{Research Design}

The experimental design consisted of four stages. During the first stage, the development of the software was planned. In this stage, rapid prototyping methodology was used, after a process of reaching the application requirements, an initial design was developed and in a cyclical way, versions were created with limited functionality applications to test with users. These iterations allowed the research team to improve the application until reaching a level of functionality according to the established requirements. Simultaneously, a question database was designed in an Excel format, with attachments corresponding to audio files and images with a creative common license, with more than a thousand exercises of different formats (vocabulary, grammar and listening exercises) to meet the language content in accordance with the A1 Language Program of the Languages Institute where the application was used.

After selecting the sample and having the content of the selected application, the third phase consisted in the use of the application by the students during an academic semester. A survey was applied to the groups of students that used the application, in order to know their appreciations on the contextualized application and the benefits or advances that they have had in the learning of the foreign language. This analysis was performed through statistical analysis of variance.

\section{Results}

The above can be evidenced in the result scores that were achieved by the students in the graphs that are presented below, in which a comparison was made between the groups in order to demonstrate that the use of the mobile application in the test groups (test) has a positive impact on the students' academic performance. In order to show the benefit of using the mobile application, four separate comparisons were made pairing a control and a test group according to the following criterion: candidate groups whose initial results were similar in the diagnostic test. First, the control group 1 and the test group 5 were compared as shown in the graph below. 
Results Control group 1 Vs. Test group 5
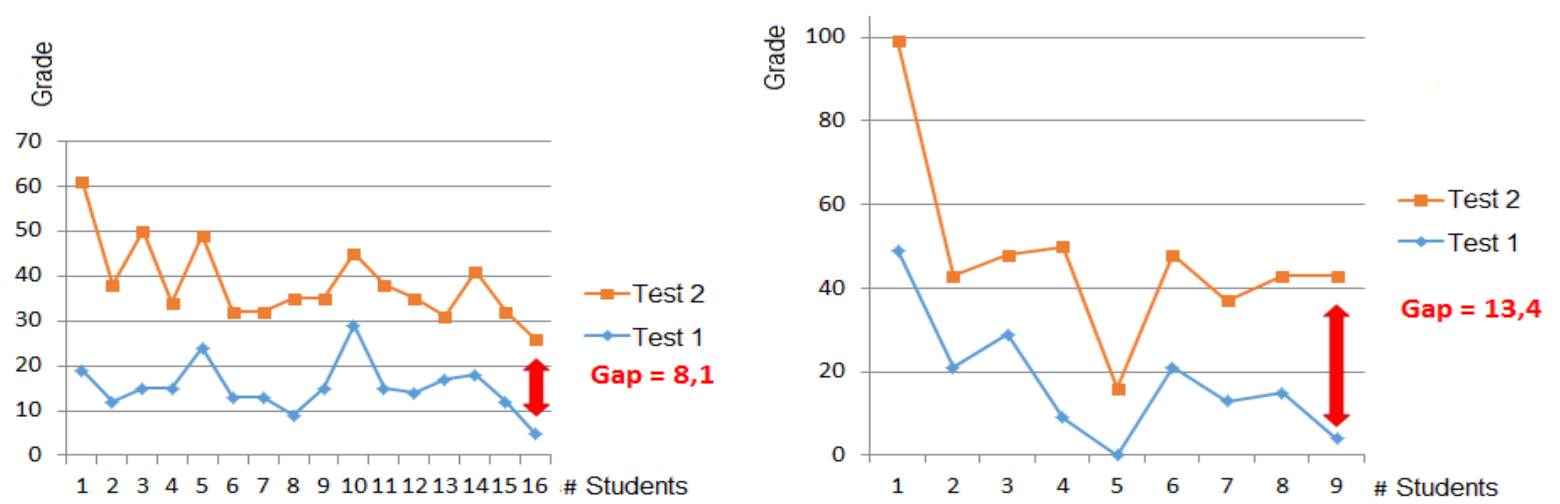

Figure 1. Control 1 vs. Test 5

From the above, it is derived that the difference of the results in control group 1 is 8.1 points and the difference of the result in test group 5 is 13.4 points which show a favorable inequality in the group that used the mobile application.
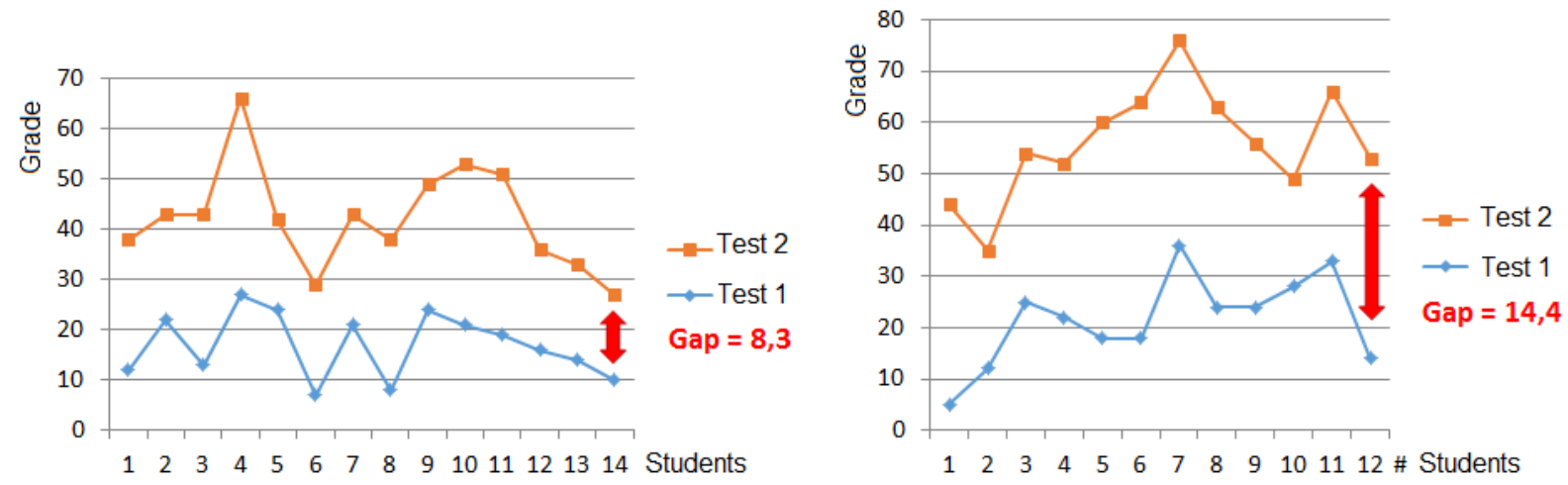

Figure 2. Control 6 vs. Test 2

Likewise, there is a significant variation in test group 2, which corresponds to 14.4 points in the result of the test applied as a consequence of the use of the mobile application in the English classes. Contrary to what happened in control group 6 , whose difference of results reaches 8.3 points.

Results Control group 3 Vs. Test group 4
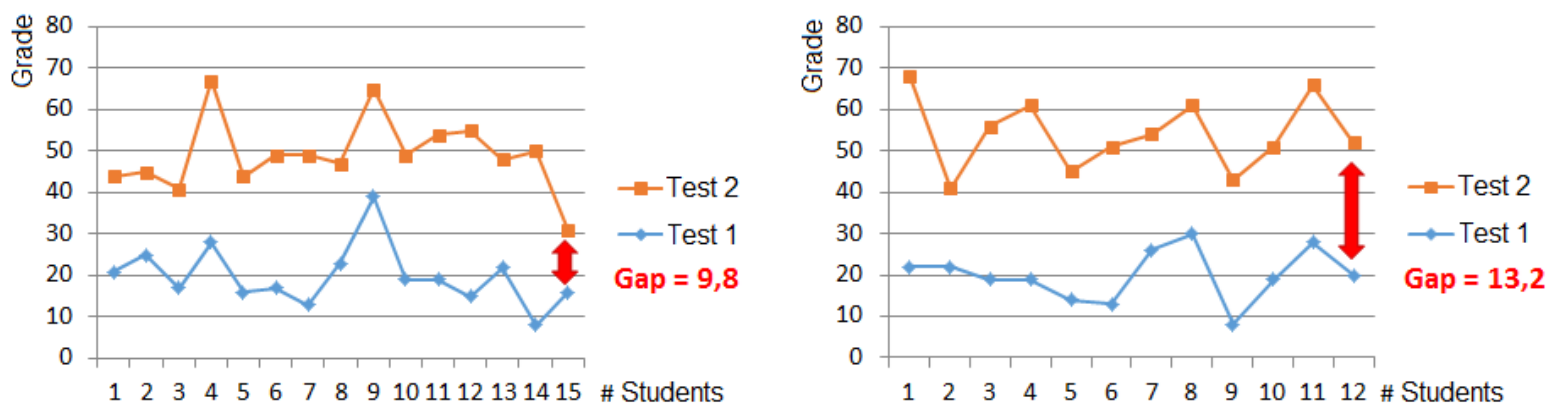

Figure 3. Control 3 vs. Test 4 
The graph again shows a disparity in favor of test group 4 where students had access to the mobile application with respect to control group 3 that did not use said tool. The difference between the results of the initial and final test of test group 4 was 13.2 points while the results average of the same in control group 3 was 9.8 points. Finally, when comparing the results of control group 8 and those of test group 7, it was observed that the group 7 obtained a variation of these corresponding to 7.8 points while in control group 8 a difference of 6.1 points was reached as observed in the graph below.

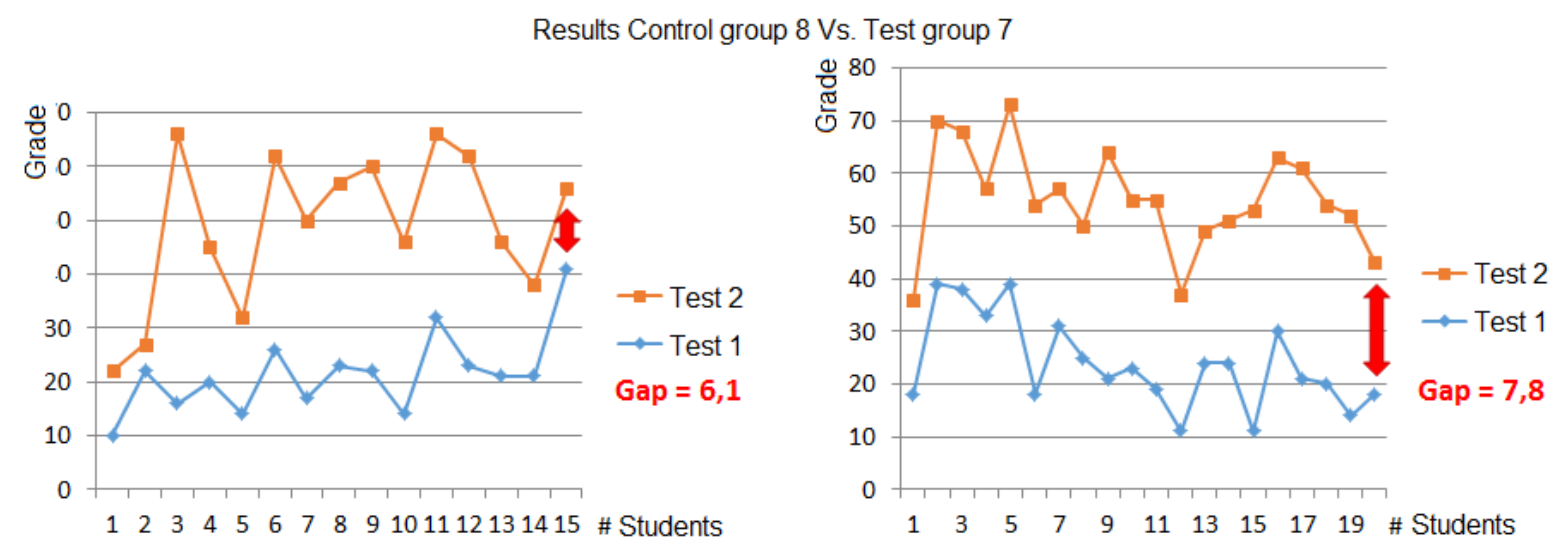

Figure 4. Control 8 vs. Test 7

When analyzing the results obtained by the test groups, it is observed that the implementation of the mobile application allows a statistically significant improvement in the development of both linguistic and listening competencies of the students of level A1 of English of Santiago de Cali University.

In order to gather more subjective opinions regarding the way the members of the test groups perceived the implementation and benefit of the application in their process of learning the foreign language (English), an end-of-semester survey was carried out. It sought to know whether they noticed an additional benefit that could be derived from the access to an application that was aligned with the content of the English course they were taking. The students' comments corroborated the main objective of using the contextualized application to their learning needs.

The table below shows the impressions of students using mobile technology.

Table 1. Results of the survey

\begin{tabular}{ll}
\hline Question & Answer \\
\hline How useful do you think the app is for you? & Very useful: $50 \%$ \\
& It is a plus: $50 \%$ \\
How often do you think you should use this & On a daily basis: $63 \%$ \\
application? & Once a week: $32 \%$ \\
& Once a month: $5 \%$ \\
How well do you think you understood what & Very good: $38 \%$ \\
the application intended to achieve? & Well: $56 \%$ \\
& Little: $6 \%$ \\
What did you like $\quad$ best $\quad$ about & Interactive and easy to understand: $13 \%$ \\
application? & The subjects and types of exercises: $50 \%$ \\
& Accessibility and ease of use: $24 \%$ \\
\hline
\end{tabular}


Everything: $13 \%$

What is the main benefit you have received from the application?
The opportunity to practice consistently: $8 \%$

Improve vocabulary: $42 \%$

Learn both grammar and vocabulary: $25 \%$

Greater contact with the language (listening): $25 \%$

Yes: $88 \%$

No: $12 \%$

\subsection{Participant Flow}

The total number of students who participated in the current study was 113 divided into eight groups. In group 1, seventeen students were part of the initial test and only one student did not complete the second test. A similar situation occurred in group 2 , in which thirteen students started the project and one did not complete it. The total number of participants in group 3 was eighteen with two students dropping out. A significant difference of participants was shown in group 4 with a total of twenty-three students at the beginning of the semester and only twelve fulfilled the task. In group 5, fifteen students participated in the initial test and nine completed it. In group 6 , sixteen participants took the exam at the beginning of the semester and only one student did not complete the final test. In group 7, a total of twenty-five students were part of the project and five students did not accomplish it. Group 8 was the only group in which the initial and final number of participants in the project remained the same in both tests.

\section{Discussion}

The use of mobile applications for language learning and English, in particular, has become popular in recent years due to the growing use of mobile phones and other portable devices from younger generations and the rise of the concept of $\mathrm{m}$ - Learning (mobile learning) in different academic fields. However, the use of applications for the learning of English - and particularly for the development of the linguistic and auditory competencies of the foreign language in Higher Education Institutions in Colombia - is rather scarce.

In the review of the literature on m-learning and the use of applications for learning English, several articles state the research on the integration of educational platforms and mobile applications in different educational contexts. For the purposes of the discussion, three have been selected that are closely related to the study developed.

At the 12th International Scientific Conference on e-learning and software for Education held in Bucharest in April 2016, the paper entitled "The Teaching of Foreign Languages through the Use of Mobile Applications in Educational Platforms Integrated "by Ionita M and Asan D. This document establishes that to facilitate the acquisition of linguistic knowledge, the use of m-learning has been configured as an inherent part of the educational process in contemporary digital society. The use of such devices has become a trend of high impact worldwide given the characteristics of learning mediated by mobile technology. These have been integrated into the teaching of languages thanks to their potential to expand the autonomy of learning. The main objectives of this study were to present an overview of the mobile applications used in the teaching of foreign languages under the m-learning modality and the analysis of the impact of these applications on the language comprehension and production skills (specifically in the German language). The research took as reference three applications recognized in the market: Duolingo, Lern Deutsh and Tandem. One of the main conclusions of this study shows that most of the content of the application has already been acquired by students through methods or practices made in advance in class. As for spelling, grammar and syntax exercises, there are little activities that reflect little student progress, while listening exercises allow improvement of pronunciation. The study concludes that under the modality of m-learning, students have a low-cost tool that is entered in real time which results in a change in user behavior and perception of traditional teaching methods as boring and outdated.

In general terms, the study carried out by Ionita and Asan (2016) is quite similar to the research presented here, considering that both types of research show that mobile applications for educational purposes enhance the autonomous work of students and have ample access. However, the development of a contextualized application as a complement to the practice of English in the University of Santiago de Cali, allowed a significant advance in the improvement of the auditory and linguistic competencies of students thanks to the types of exercises 
proposed in it, to Ionita and Asan (2016), who resorted to the use of existing applications in the market.

In the second study selected, Steel (2012), shows the use of mobile applications by university students learning a foreign language and how students use the applications to maximize the effectiveness of learning time outside the classroom at As well as the benefits that these applications bring to the acquisition of the language. The results obtained by Steel (2012) are similar to those achieved in the present study considering that the students reported in both investigations that the mobile applications allow the constant practice of the foreign language thanks to the ease of use of these, the possibility To access and carry the application on their cell phone, the types of exercises or activities of an interactive nature, the convenience for their use in terms of time gain and portability added to learning elements of the language such as: vocabulary and grammar. The results of question 6 of the survey conducted at Santiago de Cali University show that the main benefit that has been received from the application was: The opportunity to practice constantly, improve vocabulary, learn more grammar and vocabulary, the application is According to what you see in class, allows you to practice whenever you want, is an application that allows independent work and may be in greater contact with the language.

Steel's findings coincide with the present study, which indicates that foreign language students currently use various types of strategies to improve their learning as mobile technology generates greater exposure to the language outside the time spent learning in the classroom.

Finally, the study of Aguilera, Fúquene, and Ríos (2014) who described the use of the Duolingo application at the University of La Salle in order to encourage learning or improve the English proficiency of students in the Business and International Relations program was consulted. This application was used as an autonomous learning strategy that includes elements of gamification. Unlike the USC research, this study did not apply a test before and after the use of the application which prevented academics from validating the results obtained and to be able to evaluate the impact and scope of the application. In the case of the research developed at Santiago de Cali University, not only positive results were obtained against the students' performance in the tests applied to verify if the application allowed the improvement of the auditory and linguistic competencies, but also perceptions favorable to Close to the use of the application in question 3 on the frequency of use of the same. $63 \%$ of the respondents said that the application should be used every day and $50 \%$ of the students who used it find in their content a very useful strategy for the development of foreign language skills.

In conclusion, and following Kukulska-Hulme's (2012) approach, individual review of students' experiences in certain contexts allows researchers and the academic community involved in language teaching to work together to build a practice based on the use of mobile technologies and how they fit into language learning.

\section{Limitations and Future Research}

This research has several limitations that must be marked. First, it was conducted on a small scale since the total number of students at Santiago de Cali University is close to 15.000. Thus, future research might expand the number of participants in order to better predict the impact of the mobile application on the development of the language skills. That way, the researchers could explore in a broader sense the linguistic content of the app and its real use. Nevertheless, the results obtained in the current study are significant since there is evidence of the betterment of the academic performance of students in the language classes at Santiago de Cali University.

\section{References}

Aguilera, A., Fúquene, C., \& y Ríos, W. (2014). Aprende jugando: el uso de técnicas de gamificación en entornos de aprendizaje. IM-Pertinente, 2(1), 125-143.

Beishuizen. (2008). Does a community of learners Foster self-regulated learning? Technology, Pedagogy, and Education, 17(3), 182-193.

Deterding et al. (2011). Gamification: using game elements in non-game contexts.

English Proficiency Index (EPI): http://www.ef.com.co/epi/

Essential Computer Facts about the Computer and Video Game Industry. ESA (2013) http://www.isfe.eu/sites/isfe.eu/files/attachments/esa_ef_2013.pdf

García Peñalvo, F., \& Safont, L. (2013). ASPECTOS PEDAGÓGICOS EN LA INFORMÁTICA EDUCATIVA. Teoría de la Educación. Educación y Cultura en la Sociedad de la Información [en linea] 2013, 14. http://www.redalyc.org/articulo.oa?id=201028055016

Glover. I. (2013). Play as you learn: Gamification as a technique for motivating learners. Sheffield Hallam University Research Archive. 
Ionita, M., \& Asan, D. (2016). LEARNING FOREIGN LANGUAGES BY USING MOBILE APPS WITHIN INTEGRATED EDUCATIONAL PLATFORMS. Paper presented at the, 2 115-120.

Jordan. (2012). Games and Learning: Gamification in formal educational settings. The university of Hawaii at Manoa. https://pdfs.semanticscholar.org/b1e9/042863e712d13cb788bcd807d51267d51017.pdf

Jovanovic, M., Starcevic, D., Minovic, M., \& Stavljanin, V. (2011). Motivation and Multimodal Interaction in Model-Driven Educational Game Design. Systems, Man and Cybernetics, Part A: Systems and Humans, IEEE Transactions on, 41(4), 817-824. https://doi.org/10.1109/TSMCA.2011.2132711

Kukulska-Hulme. (2012). Language learning defined by time and place: A framework for next generation designs. In Diaz-Vera, Javier. (Eds.), U.K. Emerald Group Publishing Limited 1-13. https://doi.org/10.1108/S2041-272X(2012)0000006004

Lee \& Hammer. (2011). Gamification in Education: What, How, Why bother? En: Academic Exchange Quarterly, 15(2).

$\mathrm{Ma}$ et al. (2011). Serious games and edutainment applications. London: Springer. https://doi.org/10.1007/978-1-4471-2161-9

Osman, M, El-Hussein \& Cronje. (2010). Defining Mobile Learning in the Higher Education Landscape. Educational Technology \& Society, 13(3), 12-21.

Patten, S., \& Tangney. (2006). Designing collaborative, constructionist and contextual applications for handheld devices. Computers and Education 46, 294-308. https://doi.org/10.1016/j.compedu.2005.11.011

Programa Nacional de Inglés 2015-2025. "Colombia Very Well" http://www.colombiaaprende.edu.co/html/micrositios/1752/articles-343287_recurso_1.pdf

Sánchez Jabba, Andrés. Bilingüismo en Colombia. Documentos de trabajo sobre economía regional. Número 191, Agosto de 2013. Banco de la República.

SCOPEO Monográfico No.3 "M-learning en España, Portugal y América Latina" (2011). http://scopeo.usal.es/wp-content/uploads/2013/04/scopeom003.pdf

Steel. (2012). Fitting learning into life: Language students' perspectives on benefits of using mobile apps. http://www.ascilite.org/conferences/Wellington12/2012/images/custom/steel,_caroline__ffitting_learning.p $\mathrm{df}$

UNESCO. (2013). "The Future of Mobile Education" http://unesdoc.unesco.org/images/0021/002196/219637e.pdf

Wendy Hsin-Yuan Huang y Dilip Soman (2013). A practitioner's guide to Gamification of Education. Rotman School of Management. The university of Toronto. www.rotman.utoronto.ca/-/.../guidegamificationeducationdec2013

Muller, J; Wood, De Pasquale, \& Cruikshank (2012). Examining Mobile Technology in Higher Education: Handheld devices in and out of the classroom. International Journal of Higher Education, 1(2), 43-54. https://doi.org/10.5430/ijhe.v1n2p43

Zichermann \& Cunningham. (2011). Game Mechanics: Designing for Engagement (part I). In Gamification by design: Implementing game mechanics in web and mobile apps, 57-59. https://doc.lagout.org/programmation/Game\%20Design/Gamification\%20by\%20Design\%20-\%20Zicherma nn\%2C\%20Cunningham\%20-\%20O\%27Reilly\%20\%282011\%29/Gamification\%20by\%20Design\%20-\%2 0Zichermann\%2C\%20Cunningham\%20-\%20O\%27Reilly\%20\%282011\%29.pdf

\section{Copyrights}

Copyright for this article is retained by the author(s), with first publication rights granted to the journal.

This is an open-access article distributed under the terms and conditions of the Creative Commons Attribution license (http://creativecommons.org/licenses/by/4.0/). 